\title{
Safety and Efficacy of Pegylated Interferon alpha-2a and Ribavirin Combination in Treatment of Egyptian Patients with Chronic Hepatitis C Genotype-4
}

\author{
Abdel-Hameed I.M. Ebid ${ }^{1}$, Abdallah Atef Derbala ${ }^{1}$, Ahmed A. Gomaa ${ }^{2}$ \\ ${ }^{I}$ Department of Pharmacy Practice, Faculty of Pharmacy, Helwan University. Cairo, Egypt. \\ ${ }^{2}$ Department of Tropical Medicine, Faculty of Medicine, El-Fayoum University. El-Fayoum, Egypt
}

\begin{abstract}
Introduction: Egypt has the highest hepatitis C virus (HCV) seroprevalence in the world mostly caused by HCV genotype 4. The standard of care for chronic hepatitis $\mathrm{C}(\mathrm{CHC})$ is a combination of pegylated interferon (INF) and ribavirin $(R B V)$. A new locally manufactured pegylated INF with different pegylation chemistry than products with well characterized clinical profiles has been introduced into the Egyptian market with a much lower price. Little is known about the safety and efficacy of this product. So, the aim of this study is to comprehensively evaluate the safety and efficacy of this product.
\end{abstract}

Patients and methods: A total of 97 treatment naïve patients with CHC genotype 4 with mean age $46.68 \pm 8.76$ years old of whom 79 were males and 18 were females, were treated with pegylated INF alpha-2a and RBV for 48 weeks. Patients were monitored for safety and efficacy during the treatment and 24-week follow up periods.

Results: fifty-one (52.58\%) patients achieved a sustained virological response (SVR). The rate of SVR varied significantly by age, baseline fibrosis stage, aspartate aminotransferase (AST), alanine aminotransferase (ALT), alpha fetoprotein (AFP), and (WBC). Most adverse effects were mild to moderate in severity and were well tolerated. The overall continuance rate without dose reduction was 37.11\%. Three patients discontinued treatment, one died and the others discontinued due to fundal hemorrhage and neutropenia, respectively. Hematologic toxicity included anemia with a frequency $60.82 \%$, neutropenia $4.12 \%$, and thrombocytopenia $1.02 \%$.

Conclusion: The efficacy and safety profile of the drug is comparable to previously approved original products. Considering its low cost, it represents an opportunity to fight the HCV epidemic in Egypt at reasonable an affordable costs.

KEYWORDS - HCV, Interferon, Ribavirin, SVR.

\section{INTRODUCTION}

Hepatitis $\mathrm{C}$ virus $(\mathrm{HCV})$ is a hepatotropic RNA virus with a propensity to cause chronic infection, causing a worldwide burden of chronic hepatitis (CHC), cirrhosis and hepatocellular carcinoma (HCC). HCV infection is the principal cause of chronic liver disease and hepatocellular carcinoma and the leading indication for liver transplantation [1]. Nearly 123 million people worldwide are currently infected with the HCV [2] and approximately 3.2 to 5 million of these individuals are in the United States [3]. In Egypt, the situation is quite worse. The national prevalence rate of HCV antibody positivity estimated at $14.7 \%$ of the country's population [4,5] with an estimated $91 \%$ of infections are caused by genotype 4[6]. So, Egypt has the highest HCV seroprevalence in the world [7, 8]. Today, HCV infection and its complications are among the leading public health challenges in Egypt [9].The current standard of care for chronic hepatitis $\mathrm{C}$ is a combination of pegylated interferon (INF) alpha and ribavirin (RBV). Two pegylated formulations of IFN alpha, a 40-kDa pegylated IFN alpha-2a and a 12-kDa pegylated IFN alpha-2b, have been developed and tested clinically and approved for use in the United States [10,11]. The cost of such treatment in Egypt was quit prohibitive until a locally manufactured biosimilar of pegylated IFN was produced and led to a 6 -fold reduction in the price of a 48-week treatment course of pegylated IFN and RBV which currently costs less than US \$2000[12]. However, this generic biosimilar is structurally different from the original approved pegylated IFN alpha-2a. It consists of 20-kDa linear pegylated INF alpha-2a instead of 40-kDa branched pegylated INF alpha 2-a [13]. Difference in pegylation chemistry reflects on pharmacokinetics, specific antiviral activity and possibly on clinical profile [14]. Although safety and efficacy data for generic interferon is limited, it has been widely used by the Health Insurance Organization (HIO) in Egypt to treat CHC patients. Therefore, the aim of this study was to investigate the safety and efficacy of $20-\mathrm{kDa}$ linear pegylated INF alpha-2a and ribavirin in treatment of Egyptian patients with CHC genotype 4 as well as studying the various factors that may affect patients' response to treatment. 


\subsection{Patient Selection:}

\section{PATIENTS AND METHODS}

Adult Egyptian patients with previously untreated CHC that were enrolled for treatment at Fayoum Health Insurance Hospital were screened in the period from April 01, 2012 to April 30, 2012 and entered the study if they: were aged 18-65 years old, had at least one elevated serum alanine aminotransferase (ALT) level more than twice the upper limit of normal during the 6 months before treatment, had positive serum anti-HCV antibodies, had a detectable HCV-RNA on testing with polymerase chain reaction (PCR), and agreed to sign an informed consent to participate in the study.

Patients were excluded from the study if they: don't meet the above mentioned inclusion criteria, had other causes of chronic liver disease (hepatitis B infection, autoimmune hepatitis, metabolic liver disease such as hemochromatosis or chronic alcoholism), were co-infected with human immunodeficiency virus (HIV), were pregnant or breast feeding females, had ischemic heart disease (IHD), had severe neurologic or psychological conditions, had hematologic conditions such as white blood cell (WBC) count $<3.5 \times 10^{6} / \mathrm{mm}^{3}$, absolute neutrophilic count (ANC) $<1500 / \mathrm{mm}^{3}$, hemoglobin $(\mathrm{Hg})<12 \mathrm{gm} / \mathrm{dl}$, or platelet (PLT) count $<100,000 / \mathrm{mm}^{3}$, or had autoimmune disease, hemolytic anemia, or poorly controlled diabetes mellitus $\left(\mathrm{HbA}_{1 \mathrm{c}}>8.5 \%\right)$.

\subsection{Treatment:}

Selected patients were assigned to receive $160 \mu \mathrm{gm}$ of 20 -kDa linear pegylated INF alpha-2a (Reiferon Retard®; Rhein-Minapharm Inc.) once a week for 48-weeks and ribavirin (Ribavirin ${ }^{\circledR}$; Minapharm Inc.) 1000 $\mathrm{mg}$ /day for patients weighing $<75 \mathrm{~kg}$ and $1200 \mathrm{mg}$ /day for patients weighing $>75 \mathrm{~kg}$. INF dose was reduced to $120 \mu \mathrm{gm} /$ week if: ANC $<750 / \mathrm{mm}^{3}$, PLT $<50,000 / \mathrm{mm}^{3}, \mathrm{Hg}<8.5 \mathrm{~g} / \mathrm{dl}$. INF administration was temporarily suspended if ANC $<500 / \mathrm{mm}^{3}$ and was permanently discontinued if ANC $<350 / \mathrm{mm}^{3}$ or PLT $<25,000 / \mathrm{mm}^{3}$. $\mathrm{RBV}$ dose was reduced to $600 \mathrm{mg} /$ day if $\mathrm{Hg}<10 \mathrm{gm} / \mathrm{dl}$.

\subsection{Monitoring:}

Patients were carefully monitored every week for the first 2 weeks and at $4^{\text {th }}$ week then every 4 weeks by physical examination with stress on treatment induced adverse effects together with laboratory parameters evaluations that included: complete blood picture (CBC), aspartate aminotransferase (AST), ALT, total bilirubin, international normalized ratio (INR), serum creatinine, thyroid stimulating hormone (TSH) level, and alpha fetoprotein (AFP) level. Serum HCV-RNA levels were measured at $12^{\text {th }}, 24^{\text {th }}, 48^{\text {th }}$, and $72^{\text {nd }}$ weeks of treatment.

\subsection{Virologic Assessment and Definition of Virologic Response:}

HCV-RNA was quantified by Amplicor Monitor Assay; Roch Molecular Systems. The specimen requirement for HCV-RNA by PCR is one EDTA Serum needs to be separated from cells within 6 hours of collection and refrigerated or frozen to avoid degradation of viral RNA. A DNA copy of viral RNA is synthesized by reverse transcription. This DNA molecule is amplified millions of times by PCR. The lower limit of detection for the assay was $6 \mathrm{KIU} / \mathrm{ml}$. The early virological response (EVR) was defined as more than 2-log reduction in HCV-RNA compared with baseline or undetectable HCV-RNA at $12^{\text {th }}$ week of treatment; the end of treatment response (ETR) as undetectable HCV-RNA at the end of the 48-week course of treatment; and sustained virological response (SVR) as undetectable HCV-RNA 24 weeks after finishing treatment. Patients with less than 2-log reduction in HCV-RNA at $12^{\text {th }}$ week of treatment were considered non-responders and had to discontinue treatment according to hospital protocol. This was also done with patients who showed reappearance of HCV-RNA while on treatment (breakthrough response). Relapse is defined as reappearance of HCV-RNA after finishing the course of treatment. Anti-viral efficacy was evaluated for all study patients using intention-to-treat analysis (ITT analysis).

\subsection{Statistical Analysis:}

Results are presented as means \pm standard deviations (SD) and range for continuous variables, median and range for non-normally distributed variables, and as frequencies and percentages for categorical data.

Analysis of normality was performed using the Kolmogorov-Smirnov test. Categorical data and proportions were analyzed using the $\chi 2$ test or the Fisher's exact test, as required. Student's t test was used to compare the means of the 2 groups with normal distributions, and the Mann-Whitney U test was used to compare variables with non-normal distributions. All tests were 2-tailed. P-values $<0.05$ were considered statistically significant. Analysis was conducted using SPSS version 22. 


\subsection{Baseline Characteristics:}

\section{RESULTS}

The study was performed from April 2012 to September 2013 at Fayoum Health Insurance Hospital. A total of 97 treatment naïve Egyptian CHC patients were studied of whom 79 (81.45\%) were males and 18 $(18.55 \%)$ were females. The mean age for studied patients was $46.68 \pm 8.76$ years old. Table 1 summarizes the baseline demographic and clinical data for the studied population.

\subsection{Adverse Events (AEs):}

All patients had at least one AE during treatment. Most treatment-related AEs were considered mild or moderate in severity and were consistent with flu-like symptoms such as fever, headache, and fatigue. All AEs reported with a frequency of at least $10 \%$ are summarized in Table 2. Treatment-related serious adverse events (SAEs) included fundal hemorrhage (1 patient) that required treatment discontinuation $16^{\text {th }}$ week and resulted in breakthrough response, thyroid dysfunction (1 patient) that required thyroid hormone replacement. One patient died during the study in the $34^{\text {th }}$ week of treatment due to febrile neutropenia with severe thrombocytopenia.

\subsection{Clinical Laboratory Evaluation:}

Most changes in laboratory values were mild or moderate, as classified by World Health Organization (WHO) criteria. Grade $3\left(500\right.$ to $\left.<750 / \mathrm{mm}^{3}\right)$ and grade $4\left(<500 / \mathrm{mm}^{3}\right)$ neutropenia occurred in $3(3.1 \%)$ and 2 $(2.1 \%)$ patients, respectively. One of the patients with grade 4 neutropenia discontinued treatment at week 32 (ANC $345 / \mathrm{mm}^{3}$ ) but achieved an SVR, and the other had improved counts when re-tested and was managed with suspending IFN doses for 2 weeks. The magnitude of reductions in hemoglobin concentration from baseline was similar in all age groups. At nadir, the mean change from baseline ranged from - $4.1 \mathrm{~g} / \mathrm{dl}$ to -4.2 g/dl. Anemia was managed through dose reduction of RBV in $47(48.45 \%)$ patients and 12 patients $(12.37 \%)$ required both IFN alfa-2a and RBV dose reduction.

Table 1: Patients' baseline demographic and clinical features.

\begin{tabular}{|c|c|}
\hline Characteristic & Value \\
\hline Number of patients & 97 \\
\hline Age $^{*}$ (years) & $46.68 \pm 8.76$ \\
\hline Sex (male/female) & $79 / 18$ \\
\hline Body Weight* ${ }^{*}(\mathrm{~kg})$ & $63.4 \pm 12.23$ \\
\hline $\operatorname{Albumin}^{*}(\mathrm{~g} / \mathrm{dl})$ & $4.4 \pm 0.44$ \\
\hline $\operatorname{ALT}^{*}(\mathrm{IU} / \mathrm{L})$ & $67.39 \pm 33.44$ \\
\hline $\operatorname{AST}^{*}(\mathrm{IU} / \mathrm{L})$ & $62 \pm 30.15$ \\
\hline $\operatorname{ALP}^{*}(I U / L)$ & $116.21 \pm 43.84$ \\
\hline $\operatorname{AFP}^{* *}(\mathrm{ng} / \mathrm{ml})$ & $4.7 / 0.2-120$ \\
\hline Total Bilirubin*(mg/dl) & $0.85 \pm 0.35$ \\
\hline Serum Creatinine ${ }^{*}(\mathrm{mg} / \mathrm{dl})$ & $0.76 \pm 0.17$ \\
\hline $\mathrm{WBC}^{*}\left(\times 1000 / \mathrm{mm}^{3}\right)$ & $5.81 \pm 1.72$ \\
\hline $\operatorname{Hemoglobin}^{*}(\mathrm{~g} / \mathrm{dl})$ & $13.90 \pm 1.25$ \\
\hline $\operatorname{PLT}^{*}\left(\times 1000 / \mathrm{mm}^{3}\right)$ & $201.09 \pm 70.450$ \\
\hline $\mathrm{TSH}^{*}(\mathrm{mIU} / \mathrm{L})$ & $1.27 \pm 1.0$ \\
\hline Fasting blood glucose ${ }^{*}(\mathrm{mg} / \mathrm{dl})$ & $91.93 \pm 24.81$ \\
\hline $\mathrm{HbA}_{1 \mathrm{c}}{ }^{* * * *}(\%)$ & $6.8 \pm 0.65$ \\
\hline $\operatorname{Viral~load}^{* * \cdot * * * *}(\mathrm{KIU} / \mathrm{ml})$ & $180 / 0.1-4116$ \\
\hline METAVIR fibrosis score $(0-2 / 3-4)$ & $70 / 27$ \\
\hline METAVIR activity score $(0-1 / 2-3)$ & $40 / 57$ \\
\hline
\end{tabular}

ALT: alanine aminotransferase; AST: aspartate aminotransferase; ALP: alkaline phosphatase; AFP: alpha-feto protein; WBC: white blood cells; PLT: platelets; TSH: thyroid stimulating hormone; HbA 1 : Glycated hemoglobin.* mean $\pm \mathrm{SD}, * *$ median / range, $* * *$ for patients with fasting blood glucose $>126 \mathrm{mg} / \mathrm{dl}(\mathrm{n}=4)$. $* * * * 1 \mathrm{KIU} / \mathrm{ml}=900 \mathrm{copies} / \mathrm{ml}$. 


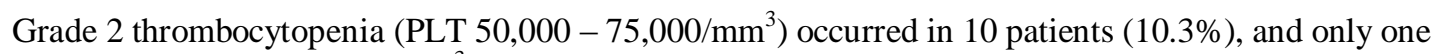
patient $(1.03 \%)$ had grade $3\left(49,000 / \mathrm{mm}^{3}\right)$ that was managed by INF dose reduction. Twenty-two patients (22.68\%) had at least one abnormal thyroid-stimulating hormone (TSH) value during the treatment, and one $(1.03 \%)$ had clinical hypothyroidism for whom levothyroxine replacement was used to manage. Table 3 summarizes laboratory abnormalities encountered during treatment.

Table 2: Treatment related adverse events stratified by age (> 10\% incidence in all patients)

\begin{tabular}{|c|c|c|c|c|}
\hline AE, n (\%) & $18-35 Y(n=16)$ & $36-50 Y(n=43)$ & $51-65 Y(n=38)$ & All Patients $(n=97)$ \\
\hline \multicolumn{5}{|c|}{ General constitutional symptoms } \\
\hline Fever & $14(87.5 \%)$ & $37(86 \%)$ & $29(76.32 \%)$ & $80(82.47 \%)$ \\
\hline Chills & $4(25 \%)$ & $7(16.28 \%)$ & $12(31.58 \%)$ & $23(23.71 \%)$ \\
\hline Fatigue & $8(50 \%)$ & $21(48.84 \%)$ & $20(52.63 \%)$ & $49(50.52 \%)$ \\
\hline Weight loss* & $2(12.5 \%)$ & $8(18.6 \%)$ & $4(10.53 \%)$ & $14(14.43 \%)$ \\
\hline ISR & $5(31.25 \%)$ & $10(23.26 \%)$ & $11(28.95 \%)$ & $26(26.8 \%)$ \\
\hline \multicolumn{5}{|c|}{ Gastrointestinal disorders } \\
\hline Nausea & $6(37.5 \%)$ & $9(10.93 \%)$ & $10(26.32 \%)$ & $25(25.77 \%)$ \\
\hline Vomiting & $3(18.75 \%)$ & $2(4.65 \%)$ & $8(21.05 \%)$ & $13(13.4 \%)$ \\
\hline Abdominal Pain & $3(18.75 \%)$ & $6(13.95 \%)$ & $7(18.42 \%)$ & $16(16.49 \%)$ \\
\hline Anorexia & $2(12.5 \%)$ & $13(30.23 \%)$ & $9(23.68 \%)$ & $24(24.74 \%)$ \\
\hline \multicolumn{5}{|c|}{ Respiratory tract disorders } \\
\hline Breathlessness & $1(6.25 \%)$ & $6(13.95 \%)$ & $5(13.16 \%)$ & $12(12.37 \%)$ \\
\hline Cough & $1(6.25 \%)$ & $3(6.98 \%)$ & $4(10.53 \%)$ & $8(8.25 \%)$ \\
\hline \multicolumn{5}{|c|}{ Musculoskeletal disorders } \\
\hline Arthralgia & $3(18.75 \%)$ & $4(9.3 \%)$ & $6(15.79 \%)$ & $13(13.4 \%)$ \\
\hline Myalgia & $4(25 \%)$ & $10(23.26 \%)$ & $10(26.32 \%)$ & $24(24.74 \%)$ \\
\hline \multicolumn{5}{|c|}{ Nervous system disorders } \\
\hline Headache & $9(56.25 \%)$ & $21(48.84 \%)$ & $24(63.16 \%)$ & $54(55.67 \%)$ \\
\hline Dizziness & $2(12.5 \%)$ & $7(16.28 \%)$ & $5(13.16 \%)$ & $14(14.43 \%)$ \\
\hline \multicolumn{5}{|c|}{ Psychological Disorders } \\
\hline $\begin{array}{l}\text { Nervousness } \\
\text { aggression }\end{array}$ & $2(12.5 \%)$ & $4(9.3 \%)$ & $5(13.16 \%)$ & $11(11.34 \%)$ \\
\hline Insomnia & $3(18.75 \%)$ & $12(27.9 \%)$ & $14(36.84 \%)$ & $29(29.9 \%)$ \\
\hline Anxiety & $2(12.5 \%)$ & $3(6.98 \%)$ & $5(13.16 \%)$ & $10(10.31 \%)$ \\
\hline Depression & $3(18.75 \%)$ & $8(18.6 \%)$ & $11(28.95 \%)$ & $22(22.68 \%)$ \\
\hline \multicolumn{5}{|l|}{ Skin disorders } \\
\hline Hair fall & $4(25 \%)$ & $12(27.9 \%)$ & $13(34.21 \%)$ & $29(29.9 \%)$ \\
\hline Pruritus & $2(12.5 \%)$ & $8(18.6 \%)$ & $7(18.42 \%)$ & $17(19.59 \%)$ \\
\hline
\end{tabular}

AE: adverse event; Y: years old; ISR: injection site reaction.

$*>5 \%$ from baseline.

Table 3: Treatment related laboratory abnormalities

\begin{tabular}{|l|c|c|}
\hline Laboratory test & Nadir, mean \pm SD & Change from baseline, mean \pm SD \\
\hline ANC, $\left(\mathbf{m m}^{\mathbf{3}}\right)$ & $1473.87 \pm 478.69$ & $-1433.35 \pm 841.66$ \\
\hline $\mathbf{H g},(\mathbf{g} / \mathbf{d l})$ & $9.69 \pm 1.13$ & $-4.21 \pm 1.55$ \\
\hline PLT, $\left(\times \mathbf{1 0 0 0} / \mathbf{m m}^{\mathbf{3}}\right)$ & $125.7 \pm 41.67$ & $-68.92 \pm 64.18$ \\
\hline TSH, $(\mathbf{m I U} / \mathbf{L})^{*}$ & $2.34 \pm 0.83$ & $1.07 \pm 1.27$ \\
\hline
\end{tabular}

ANC: Absolute Neutrophilic Count; Hg: Hemoglobin; PLT: Platelets; TSH: Thyroid Stimulating Hormone.

* Result is reported as zenith. 


\subsection{Dose Reduction / Treatment Discontinuation for AEs:}

The overall continuance rate without dose reduction was $37.11 \%$. Three patients discontinued treatment, one died at week 32 because of febrile neutropenia with severe thrombocytopenia and the other 2 patients discontinued due to fundal hemorrhage and neutropenia, respectively. IFN or RBV dose reductions were required for $60(61.86 \%)$ patients, usually because of anemia $59(60.82 \%)$, neutropenia $3(3.09 \%)$, or thrombocytopenia 1 (1.03\%). Treatment was suspended for one patient who had neutropenia (ANC $345 / \mathrm{mm}^{3}$ ). Causes and frequency of dose reduction and treatment discontinuation and their effect on viral response are summarized in Table 4.

Table 4: Adverse events leading to dose reduction or interruption.

\begin{tabular}{|c|c|c|c|}
\hline Adverse Event & Frequency, $\mathbf{n}(\boldsymbol{\%})$ & Management & SVR rate, $\mathbf{n}(\mathbf{\%})$ \\
\hline \multirow{2}{*}{ Anemia } & \multirow{2}{*}{$59(60.82)$} & 47 RBV dose reduction & $30(63.83)$ \\
\cline { 3 - 4 } & & 12 RBV \& INF dose reduction & $7(58.33)$ \\
\hline \multirow{2}{*}{ Neutropenia } & \multirow{3}{*}{$4(4.12)$} & 1Treatment Discontinuation & $1(100)$ \\
\cline { 3 - 4 } & & 1 Suspended INF & $0(0)$ \\
\cline { 3 - 4 } & $1(1.03)$ & 2 INF dose reduction & $2(100)$ \\
\hline Thrombocytopenia & $1(1.03)$ & INF dose reduction & $1(100)$ \\
\hline Fundal Hemorrhage & $1(1.03)$ & Treatment discontinuation & $0(0)$ \\
\hline Death & & N/A & $0(0)$ \\
\hline
\end{tabular}

SVR: Sustained Virological Response; INF: Interferon; RBV: Ribavirin; N/A: Not Applicable.

\subsection{Virological Response:}

Twenty-two (22.68\%) patients were non-responders, whereas 75 (77.32\%) patients attained EVR of whom $62(63.92 \%)$ had ETR and $13(13.4 \%)$ had a breakthrough response. Of the 62 patients with ETR, 11 (11.34\%) had a relapse while $51(52.58 \%)$ patients achieved SVR. Fig. 1 and Fig. 2 summarize viral responses in the studied patients.

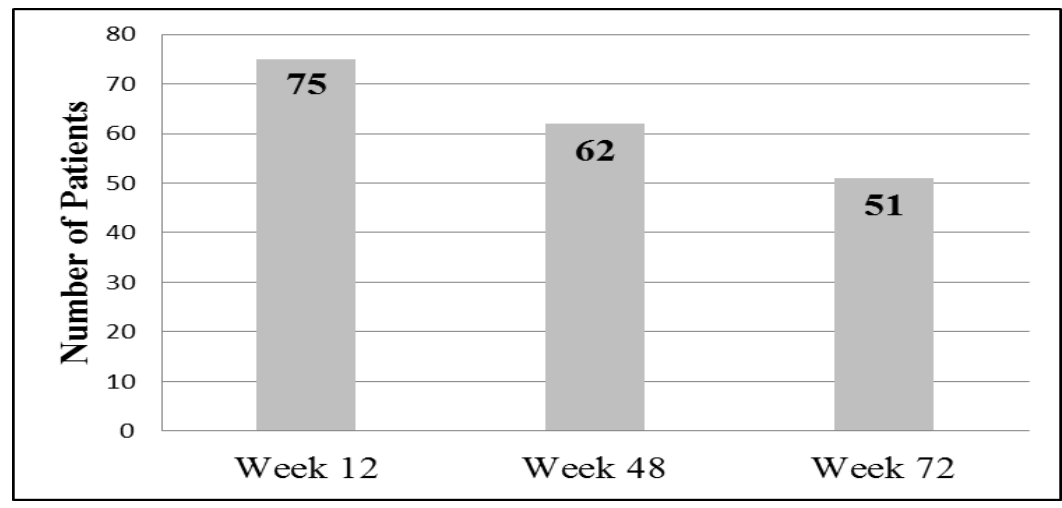

Figure 1: Number of patients with undetectable HCV-RNA by weeks of treatment.

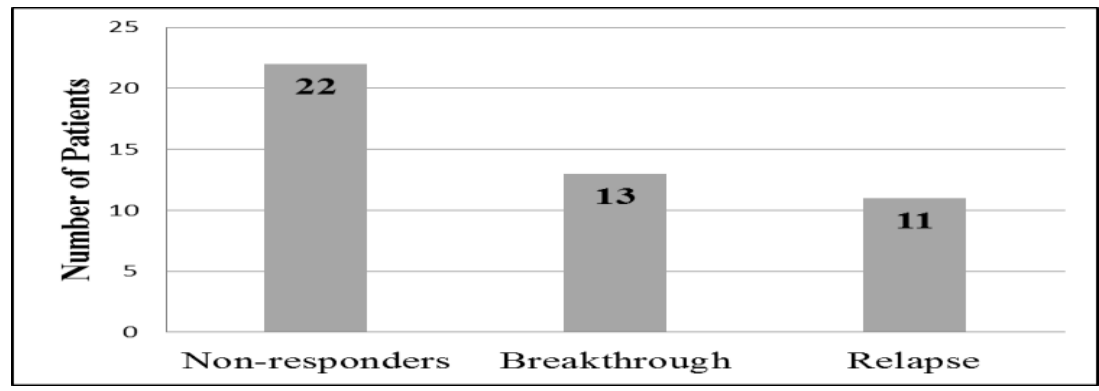

Figure 2: Patients who failed to achieve a sustained virological response. 
Factors associated with SVR were assessed using variables in Table 1. Significant factors included: age, baseline viral load, baseline METAVIR fibrosis score, AST, ALT, ALP, AFP, TSH and WBC. Table 5 summarizes the effect of studied patients' variables on SVR rate.

\section{DISCUSSION}

Egypt is confronted with an HCV disease burden of historical proportions that distinguishes this nation from others. The start of the epidemic was attributed to parenteral antischistosomal treatment campaign that took place in the 1930s which involved the use of improperly sterilized parenteral administration tools [4]. Although such treatment has discontinued since the late $1980 \mathrm{~s}$, a substantial transmission is still going in modern day Egypt [9]. Much of this transmission occurs through iatrogenic and interfamilial routes of transmission $[15,16]$. Nevertheless, a significant proportion of CHC Egyptian patients have an unknown source of infection indicating the possibility of undiscovered modes of transmission [17]. That is why treatment is considered a corner stone in the control of hepatitis C epidemic in Egypt.

Table 5: Difference in baseline variables between patients who achieved SVR and those who didn't.

\begin{tabular}{|c|c|c|c|c|}
\hline \multirow{2}{*}{\multicolumn{2}{|c|}{ Factor }} & \multicolumn{2}{|c|}{ Viral Response } & \multirow{2}{*}{$p$-value } \\
\hline & & \multirow{2}{*}{$\frac{\text { SVR }}{14}$} & \multirow{2}{*}{$\begin{array}{c}\text { Non-SVR } \\
2\end{array}$} & \\
\hline \multirow{3}{*}{ Age } & $18-35$ & & & \multirow{3}{*}{$0.003^{*}$} \\
\hline & $36-50$ & 23 & 20 & \\
\hline & $51-65$ & 14 & 24 & \\
\hline \multirow{2}{*}{ Sex } & Male & 43 & 36 & \multirow{2}{*}{0.444} \\
\hline & Female & 8 & 10 & \\
\hline \multirow{4}{*}{$\begin{array}{l}\text { Baseline Viral } \\
\text { Load*** } \\
(\mathrm{KIU} / \mathrm{ml})\end{array}$} & Very low** & 10 & 2 & \multirow{4}{*}{$0.002 *$} \\
\hline & Low** & 17 & 6 & \\
\hline & Moderate** & 20 & 26 & \\
\hline & High** & 4 & 12 & \\
\hline \multirow{2}{*}{$\begin{array}{l}\text { METAVIR } \\
\text { fibrosis }\end{array}$} & $0-2$ & 42 & 28 & \multirow{2}{*}{$0.018^{*}$} \\
\hline & $3-4$ & 9 & 18 & \\
\hline \multirow{2}{*}{$\begin{array}{l}\text { METAVIR } \\
\text { activity }\end{array}$} & $0-1$ & 34 & 23 & \multirow{2}{*}{0.096} \\
\hline & $2-3$ & 17 & 23 & \\
\hline \multicolumn{2}{|l|}{ PAlbumin $(\mathrm{gm} / \mathrm{dl})$} & $4.41 \pm 0.46$ & $4.39 \pm 0.42$ & 0.823 \\
\hline \multicolumn{2}{|l|}{ AST (IU/L) } & $55.53 \pm 20.32$ & $69.174 \pm 37.16$ & $0.03 *$ \\
\hline \multicolumn{2}{|l|}{ ALT (IU/L) } & $60.21 \pm 17.59$ & $75.35 \pm 43.80$ & $0.033 *$ \\
\hline \multicolumn{2}{|l|}{ ALP (IU/L) } & $105.65 \pm 36.42$ & $127.91 \pm 48.57$ & $0.012 *$ \\
\hline \multicolumn{2}{|c|}{ Total bilirubin**** (mg/dl) } & $0.84 \pm 0.27$ & $0.85 \pm 0.43$ & 0.878 \\
\hline \multicolumn{2}{|c|}{ Serum creatinine $* * * *(\mathrm{mg} / \mathrm{dl})$} & $0.75 \pm 0.18$ & $0.76 \pm 0.16$ & 0.716 \\
\hline \multicolumn{2}{|c|}{$\mathrm{TSH} * * * *(\mathrm{mIU} / \mathrm{L})$} & $1.44 \pm 1.13$ & $1.08 \pm 0.78$ & 0.067 \\
\hline \multicolumn{2}{|l|}{$\mathrm{WBC}\left(/ \mathrm{mm}^{3}\right)$} & $25440.78 \pm 1556.41$ & $6228.70 \pm 1810.17$ & $0.023^{*}$ \\
\hline \multicolumn{2}{|c|}{ Hemoglobin $(\mathrm{gm} / \mathrm{dl})$} & $13.91 \pm 1.41$ & $13.88 \pm 1.05$ & 0.889 \\
\hline \multicolumn{2}{|l|}{ Platelets $\left(/ \mathrm{mm}^{3}\right)$} & $210149.02 \pm 80281.83$ & $191043.48 \pm 56838.94$ & 0.184 \\
\hline \multicolumn{2}{|l|}{ "AFP*** (ng/ml) } & 4.0 & 6.40 & $0.001 *$ \\
\hline
\end{tabular}

SVR: sustained virological response; AST: aspartate aminotransferase; ALT: alanine aminotransferase; ALP: alkaline phosphatase; TSH: thyroid stimulating hormone; WBC: white blood cells; AFP: alpha feto protein.

* Statistically significant difference between SVR and non-SVR groups.

** Very low < $10 \mathrm{KIU} / \mathrm{ml}$, low < $100 \mathrm{KIU} / \mathrm{ml}$, moderate < $1000 \mathrm{KIU} / \mathrm{ml}$, high > $1000 \mathrm{KIU} / \mathrm{ml}$.

*** Results are reported as median and Mann-Whitney $\mathrm{U}$ test was used to detect significance.

**** Effect may be unclear because all patients had a normal baseline values. 
Treatment of $\mathrm{CHC}$ with pegylated INF and ribavirin combination is the current standard of care. The response this treatment varies considerably among different populations and viral genotypes. Our study demonstrates that 20-kDa pegylated INF and ribavirin combination is associated with an overall SVR rate of $52.58 \%$ in Egyptian patients with genotype 4. It is also found that the SVR rate varies significantly with age and fibrosis stage which is consistent with the published data about the same product of INF [13]. The effect of sex on SVR rate was unclear because of the relatively small number of females participating in the study. Also, we could not determine the effect of baseline serum total bilirubin, TSH, and serum creatinine because all patients had normal baseline value. The current study demonstrates that other factors that have a significant effect on SVR include: baseline viral load, AST, ALT, AFP, and WBC.

The safety and tolerability issues reported in our study is different from that reported by Esmat et al [13]. We report a $60.82 \%$ frequency of anemia $(\mathrm{Hg}<10 \mathrm{gm} / \mathrm{dl}), 4.12 \%$ for neutropenia (ANC $<750 / \mathrm{mm}^{3}$ ), one case of INF dose reduction due to thrombocytopenia, one case of death, and 2 cases of treatment discontinuation due to adverse effects. On the other hand, Esmat et al reported a 6\% frequency of anemia, 9\% for neutropenia, and no dose reduction or treatment discontinuation due to adverse effects although the studied sample is of similar size $(\mathrm{n}=100)$. It is worth mentioning that an author of that paper declared a conflict of interest of being the principal investigator in a trial sponsored by Minapharm pharmaceutical company Egypt, the producer of the product under investigation. Nevertheless, the product remains of comparable safety and tolerability with respect to published data on 40-kDa INF alpha-2a or 12-kDa INF alpha-2b [10, 11, 18-20].

\section{CONCLUSION}

Although significantly lower in price, locally manufactured pegylated INF alpha-2a has a comparable safety and Efficacy. The large scale use of such product for treatment of Egyptian CHC patients will help to combat hepatitis C epidemic in Egypt at reasonable and affordable cost. The response to pegylated INF alpha-2a and RBV combination in CHC Egyptian patients varies depending factors including: age, baseline fibrosis stage, ALT, AST, ALP, AFP, and WBC. Knowledge of these factors is important for individualized patient treatment decisions and to determine patients' priority treatment in case of scarce financial resources allocation.

Acknowledgements: None.

Conflict of Interest: The authors declare that they don't have any conflict of interest.

\section{REFERENCES}

[1] Alter, H.J. and L.B. Seeff. Recovery, persistance, and sequelae in hepatitis $C$ virus infection: a perspective on long-term outcome. in Seminars in Liver Diseases. 2000. GEORG THIEME VERLAG.

[2] Perz, J. Estimated global prevalence of hepatitis C virus infection. in $42^{\text {nd }}$ Annual Meeting. 2004. Idsa.

[3] Armstrong, G.L., et al., The prevalence of hepatitis C virus infection in the United States, 1999 through 2002 . Annals of internal medicine, 144(10), 2006, 705-14.

[4] El-Zanaty, F. and A. Way, Egypt demographic and health survey 2008. Cairo, Egypt: Ministry of Health, El-Zanaty and Associates, and Macro International; 2009.

[5] Mohamoud, Y.A., et al., The epidemiology of hepatitis C virus in Egypt: a systematic review and data synthesis. BMC Infect Dis, 13, 2013, 288

[6] Ray, S.C., et al., Genetic epidemiology of hepatitis C virus throughout Egypt. Journal of Infectious Diseases, 182(3), 2000, 698707.

[7] Lavanchy, D., Evolving epidemiology of hepatitis C virus. Clinical Microbiology and Infection, 17(2), 2005, 107-15.

[8] Alter, M.J., Epidemiology of hepatitis C virus infection. World Journal of Gastroenterology, 13(17), $2007,2436$.

[9] Miller, F.D. and L.J. Abu-Raddad, Evidence of intense ongoing endemic transmission of hepatitis C virus in Egypt. Proceedings of the National Academy of Sciences, 107(33), 2010, 14757-62.

[10] Manns, M.P., et al., Peginterferon alfa-2b plus ribavirin compared with interferon alfa-2b plus ribavirin for initial treatment of chronic hepatitis C: a randomised trial. The Lancet, 358(9286), 2001, 958-65.

[11] Fried, M.W., et al., Peginterferon alfa-2a plus ribavirin for chronic hepatitis C virus infection. New England Journal of Medicine, 347(13), 2002, 975-82.

[12] Ford, N., et al., Expanding access to treatment for hepatitis C in resource-limited settings: lessons from HIV/AIDS. Clinical infectious diseases, 54(10), 2012, 1465-72.

[13] Esmat, G. and S.A. Fattah, Evaluation of a novel pegylated interferon alpha-2a (Reiferon Retard®) in Egyptian patients with chronic hepatitis C-genotype 4. Digestive and Liver Disease Supplements, 3(1), 2009, 17-19.

[14] Luxon, B.A., et al., Pegylated interferons for the treatment of chronic hepatitis C infection. Clinical therapeutics, 24(9), 2002, 1363-83.

[15] Stoszek, S.K., et al., Prevalence of and risk factors for hepatitis C in rural pregnant Egyptian women. Transactions of the Royal Society of Tropical Medicine and Hygiene, 100(2), 2006, 102-07.

[16] Mohamed, M.K., et al., Intrafamilial transmission of hepatitis C in Egypt. Hepatology, 42(3), $2005,683-87$.

[17] Antaki, N., et al., The neglected hepatitis C virus genotypes 4, 5 and 6: an international consensus report. Liver International, 30(3), 2010, 342-55.

[18] Oze, T., et al., Indications and limitations for aged patients with chronic hepatitis $\mathrm{C}$ in pegylated interferon alfa-2b plus ribavirin combination therapy. Journal of hepatology, 54(4), 2011, 604-11.

[19] Aspinall, R. and P. Pockros, The management of side-effects during therapy for hepatitis C. Alimentary pharmacology \& therapeutics, 20(9), 2004, 917-29.

[20] Ong, J.P. and Z.M. Younossi, Managing the hematologic side effects of antiviral therapy for chronic hepatitis C: anemia, neutropenia, and thrombocytopenia. Cleveland Clinic journal of medicine, 71(Suppl 3), 2004, S17. 